\title{
Physiological tonicity improves human chondrogenic marker expression through nuclear factor of activated T-cells 5 in vitro
}

\author{
Anna E van der Windt1', Esther Haak1, Ruud HJ Das'1, Nicole Kops', Tim JM Welting², Marjolein MJ Caron², Niek P van \\ Til $^{3}$, Jan AN Verhaar ${ }^{1}$, Harrie Weinans ${ }^{1}$ and Holger Jahr*1
}

\begin{abstract}
Introduction: Chondrocytes experience a hypertonic environment compared with plasma ( $280 \mathrm{mOsm})$ due to the high fixed negative charge density of cartilage. Standard isolation of chondrocytes removes their hypertonic matrix, exposing them to nonphysiological conditions. During in vitro expansion, chondrocytes quickly lose their specialized phenotype, making them inappropriate for cell-based regenerative strategies. We aimed to elucidate the effects of tonicity during isolation and in vitro expansion on chondrocyte phenotype.

Methods: Human articular chondrocytes were isolated and subsequently expanded at control tonicity (280 mOsm) or at moderately elevated, physiological tonicity (380 mOsm). The effects of physiological tonicity on chondrocyte proliferation and chondrogenic marker expression were evaluated. The role of Tonicity-responsive Enhancer Binding Protein in response to physiological tonicity was investigated using nuclear factor of activated T-cells 5 (NFAT5) RNA interference.

Results: Moderately elevated, physiological tonicity (380 mOsm) did not affect chondrocyte proliferation, while higher tonicities inhibited proliferation and diminished cell viability. Physiological tonicity improved expression of chondrogenic markers and NFAT5 and its target genes, while suppressing dedifferentiation marker collagen type I and improving type II/type I expression ratios $>100$-fold. Effects of physiological tonicity were similar in osteoarthritic and normal (nonosteoarthritic) chondrocytes, indicating a disease-independent mechanism. NFAT5 RNA interference abolished tonicity-mediated effects and revealed that NFAT5 positively regulates collagen type II expression, while suppressing type I.

Conclusions: Physiological tonicity provides a simple, yet effective, means to improve phenotypical characteristics during cytokine-free isolation and in vitro expansion of human articular chondrocytes. Our findings will lead to the development of improved cell-based repair strategies for chondral lesions and provides important insights into mechanisms underlying osteoarthritic progression.
\end{abstract}

\section{Introduction}

Hyaline articular cartilage is a connective tissue covering the ends of bones in joints and is composed of specialized cells, chondrocytes that produce a large amount of extracellular matrix. This matrix is crucial for the unique biomechanical properties of this tissue and is composed of a collagen fiber network, providing tensile strength and

* Correspondence: h.jahr@erasmusmc.nl

1 Department of Orthopaedics, Erasmus MC, University Medical Center Rotterdam, Dr. Molewaterplein 50, 3015 GE Rotterdam, The Netherlands Full list of author information is available at the end of the article flexibility, and abundant ground matrix rich in proteoglycans [1].

The glycosaminoglycan (GAG) side chains of the proteoglycans are sulfated and responsible for a characteristic high fixed negative charge density [2], which binds mobile cations (mainly sodium). This binding determines the physiological tonicity (that is, osmotic pressure) of the extracellular fluid around chondrocytes in vivo, but the tonicity indirectly also largely depends on the quality of the collagen network. Extracellular tonicity in healthy cartilage ranges between 350 and 480 mOsm [3,4]. In 
vivo, tonicity of the extracellular fluid is dynamic and changes due to alterations in matrix hydration [5]. During cartilage degeneration (that is, in osteoarthritis (OA)), the collagen matrix degrades and the GAG concentration diminishes, resulting in a severity-dependent decreased tonicity of between 280 and 350 mOsm [3,6]. Currently, chondrocyte isolation and in vitro expansion culture are performed in medium of nonphysiological tonicity (270 \pm $20 \mathrm{mOsm})$. Several studies have already shown that chondrocytes are tonicity responsive [7-9] and react with changes in matrix synthesis $[4,8,10,11]$, but focused on aggrecan (AGC1) core protein mRNA levels, AGC1 promoter activity and GAG production.

Molecular mechanisms involved in the hypertonic response of human articular chondrocytes (HACs) are poorly understood. Hypertonicity perturbs cells by causing osmotic efflux of water, resulting in cell shrinkage $[12,13]$. Cells react by a rapid uptake of ions, which increase cellular ionic strength [14] with potentially detrimental effects [15-17]. The initial, rapid response is the activation of transporters that exchange these ions for compatible osmolytes $[16,18]$. This process is controlled by Tonicity-responsive Enhancer Binding Protein (TonEBP/NFAT5), which mediates transcriptional activation of these transporters [16]. Nuclear factor of activated T-cells 5 (NFAT5) is a member of the Rel family of transcription factors [19] and targets sodium/myo-inositol cotransporter (SMIT) [20,21], sodium/chloride-coupled acid transporters (BGT1/SLC6A12) [20], aquaporin channels (AQP1 and AQP2) [22], and calcium-binding proteins (S100A4) [23-25]. Upon hypertonic stress, transcription of NFAT5 itself is upregulated in several cell types [26-28], but the tonicity threshold and cell signaling pathways required to activate NFAT5 may be cell type specific [29]. Nothing is currently known about the expression or function of NFAT5 in HACs.

Chondral lesions from, for example, trauma or overuse, can cause joint pain, immobility and eventually OA. The associated high prevalence - $60 \%$ of all patients undergoing knee arthroscopy are diagnosed with a chondral lesion [30] - and loss of quality of life makes cartilage damage a major personal and economical burden. Treatment options for chondral lesions are limited, and autologous chondrocyte implantation is the currently most developed hyaline repair technique for the knee [31]. Characterized chondrocyte implantation, employing phenotypical prescreening prior to implantation, has recently improved structural repair [32].

Chondrocyte dedifferentiation during in vitro expansion for autologous chondrocyte implantation is detrimental; but almost inevitably in standard monolayer culture, spherical chondrocytes will gradually convert into fibroblast-like cells $[33,34]$. This morphological change is accompanied by a shift in collagen expression towards less collagen type II (COL2) and more collagen type I (COL1) [34,35]. Consequently, dedifferentiated chondrocytes produce fibrocartilage in vivo, with an extracellular matrix of inferior biomechanical properties due to higher collagen (especially type I) content and less proteoglycans compared with native hyaline cartilage [36]. Three-dimensional culture systems can partially prevent dedifferentiation, but are labor intensive and essentially impair propagation. Chondrocyte dedifferentiation might also play a role in the pathogenesis of OA, as the ability of aging chondrocytes to produce and repair the extracellular matrix is compromised [37] and as COL1 is shown to be present in chondrocyte clusters in fibrillated areas of late-stage OA cartilage while it is absent in healthy cartilage [38].

In the present article we report that physiological tonicity (380 mOsm) during isolation and monolayer expansion can suppress chondrocyte dedifferentiation and that expression of the extracelluar matrix components collagen type I and collagen type II as well as aggrecan is NFAT5 dependent. We further show that NFAT5 contributes to the differential regulation of both collagen types. This study provides a simple, yet novel and effective, means to improve cell-based repair strategies for chondral lesions and contribute to our understanding of OA progression.

\section{Materials and methods \\ Cartilage and chondrocyte isolation}

After informed consent was obtained, human articular cartilage was explanted from macroscopically normal areas of the femoral condyles and tibial plateau of nine patients undergoing total knee replacement surgery for OA (medical ethical approval MEC2004-322). In addition to preparation of cartilage explants and isolation of HACs under standard conditions (DMEM, $280 \mathrm{mOsm}$ ) as described by Das and colleagues [39], medium tonicity was also adjusted to $380 \mathrm{mOsm}, 480 \mathrm{mOsm}$ or 580 mOsm by addition of sterile $\mathrm{NaCl}$. Enzymatic digestion, removal of undigested fragments and subsequent chondrocyte culture were all reported earlier [39]. The 280 mOsm and $380 \mathrm{mOsm}$ isolations were also performed with cartilage obtained from the femoral condyles and tibial plateau of two non-OA donors (further referred to as normal donors) undergoing above-knee amputation surgery after trauma.

\section{Chondrocyte proliferation and DNA measurements}

Primary (P0), passage 1 (P1), passage 2 (P2) and passage 3 (P3) HACs were monolayer expanded in medium corresponding to their isolation tonicity ( $280 \mathrm{mOsm}, 380$ mOsm, $480 \mathrm{mOsm}$ or $580 \mathrm{mOsm}$ ), with an initial seeding density of 6,000 cells $/ \mathrm{cm}^{2}$. Cells were harvested daily for cell counts and DNA assay between days 2 and 6. Experi- 
ments were performed in duplicate from three OA donors $(n=6)$. At each passage, growth curves were established by cell counts using Trypan Blue (catalogue number T8154; Sigma-Aldrich, St. Louis, MO, USA) and DNA quantification. DNA measurements were performed according to Karsten and Wollenberger [40] with slight modifications [41]. Doubling times within each passage were calculated from the trend line of the exponential growth phase using the equation:

$$
y=x(0) \exp (k x(t)) \quad \text { with } k=\ln 2 / T
$$

where $k$ is the growth constant and $T$ is the doubling time.

\section{Chondrocyte expansion}

Primary HACs were cultured for expansion in monolayers at a seeding density of 7,500 cells $/ \mathrm{cm}^{2}$ in medium corresponding to their isolation tonicity ( $280 \mathrm{mOsm}, 380$ mOsm, $480 \mathrm{mOsm}$ or $580 \mathrm{mOsm}$ ). P0 cells to P3 cells were seeded in high-density monolayers (20,000 cells/ $\mathrm{cm}^{2}$ ) and were cultured for an additional 5 days and 7 days before analysis of mRNA (quantitative RT-PCR) and protein expression (Western blotting), respectively. Experiments were performed in triplicate from four OA donors $(n=12)$. Additional experiments were performed in triplicate from two healthy donors $(n=6)$ to investigate whether the hypertonic stress response is specific for pathologically altered cells. To exclude sodium-specific or chloride-specific effects, we performed experiments using $N$-methyl-d-glucamine chloride (NMDG-Cl) or sucrose to adjust the medium tonicity to $380 \mathrm{mOsm}$.

\section{Lentiviral NFAT5 gene knockdown}

We used lentiviral vectors for nontransient shRNA-mediated gene silencing in primary chondrocytes [42]. BamHI/MunI restriction fragments of the parental pLKO.1-puro vector - each containing the U6 promotor and one out of five different, sequence-verified antihuman NFAT5 shDNAs (MISSION shRNA library [43]) were subcloned into corresponding restriction sites of recipient vector pRRL.PPT.PGK.GFPpre. This vector was kindly provided by L Naldini (San Raffaele Telethon Institute for Gene Therapy, Milan, Italy) [44,45] and was optimized by A Schambach (Department of Experimental Hematology, Hannover Medical School, Hannover, Germany) [46] to express enhanced green fluorescent protein (eGFP) from the phosphoglycerate kinase promoter. Lentiviral particles were produced in HEK293T cells by transient transfection using a calcium phosphate protocol [47]. Cells transduced with a lentiviral vector lacking the NFAT5-specific shRNA expression cassette served as controls. All cells were grown in monolayers. TRCN0000020020 was identified as the best performing anti-NFAT5 shRNA clone by quantitative PCR-based knockdown efficiency determination, and was used in subsequent experiments.

P1 OA HACs from two donors were seeded $(15,000$ cells $/ \mathrm{cm}^{2}$ ) and cultured for 4 days in control medium (280 mOsm). Three hours prior to transduction, cells were deprived of antibiotics, and then were transduced for \pm 18 hours, refreshed with control medium with antibiotics and cultured for an additional 4 days before harvesting for fluorescence-activated cell sorting (FACS) analyses. Cells were resuspended in PBS with 10\% FCS and antibiotics, and were washed. Cells were collected and stained with Hoechst 33258 (1 mg/ml; Molecular Probes/Invitrogen Corp., Carlsbad, CA, USA) to discriminate between dead cells and live cells. FACS was performed on the FACSAria (Becton Dickinson BV, Breda, The Nederlands), and eGFP-expressing cells were collected (>50\%, multiplicity of infection $\sim 1$ ) and reanalyzed for purity (>95\%) using Cell Quest Pro Software (Becton Dickinson Biosciences BV, Breda, The Nederlands).

The eGFP-expressing populations were seeded $(10,000$ cells $/ \mathrm{cm}^{2}$ ) and cultured in control medium up to $80 \%$ confluency. Cells were then switched to medium of 380 mOsm or were kept on control medium for 24 hours prior to RNA analysis.

\section{RNA expression analysis}

RNA isolation, purification, quantification and cDNA synthesis are described elsewhere [48]. Expression levels of $A G C 1, S O X 9$ and $C O L 2$ were studied as chondrogenic markers, while COL1 was studied as a dedifferentiation marker $[34,35,49,50]$. Quantitative PCR assays for COL2, $S O X 9, A G C 1$ and $C O L 1$ have been reported earlier [51].

To quantify expression of NFAT5 and its target genes, the following primers were tested for similar amplification efficiency and specificity according to Das and colleagues [39], and were used as $20 \mu \mathrm{l} \mathrm{SYBR}{ }^{\circ}$ Green I reactions: HsNFAT5_Fw, GGGTCAAACGACGAGATTGTG and HsNFAT5_Rv, TTGTCCGTGGTAAGCTGAGAA; HsS100A4_Fw, GTCCACCTTCCACAAGTAC TCG and HsS100A4_Rv, TCATCTGTCCTTTTCCCCAAG; and HsSLC6A12_Fw, ACACAGAGCATTGCACGGACT and HsSLC6A12_Rv, CCAGAACTCGTC TCTCCCAGAA. Data were normalized to an index of three reference genes (GAPDH, UBC, HPRT1) that were pre-evaluated to be stably expressed across samples [39]. Relative expression was calculated according to the $2^{-\Delta C T}$ method [52].

\section{Western blot analysis}

Cells seeded at high densities were washed twice with PBS and were lysed in RIPA buffer [53] with addition of protease inhibitors. The total protein concentration was quantified by the bicinchoninic acid assay according to the manufacturer's protocol (\#23225; Thermo Fisher Sci., Rockford, IL, USA). Aliquots $(10 \mu \mathrm{g})$ were subjected to 
$10 \%$ SDS-PAGE prior to electroblotting onto nitrocellulose membranes (Protran BA83; Schleicher \& Schuell BV, s-Hertogenbosch, The Netherlands). Blots were blocked in $5 \%$ low-fat dry milk in $1 \times$ PBS, $0.05 \% \mathrm{v} / \mathrm{v}$ NP-40, were incubated with primary antibodies - anti-type II collagen and anti-type I collagen, both 1:100 (SouthernBiotech, Birmingham, Alabama, USA), or 1:10,000 anti- $\alpha$-Tubulin (Sigma) - were washed, were incubated with secondary antibodies (both 1:1,000; Dako Cytomation, Heverlee, Belgium) and were chemiluminescently detected. Signals were quantified using ImageJ 1.42 software [54].

\section{Statistical analysis}

Statistical analysis was performed using SPSS 13.0 software (SPSS Inc., Chicago, IL, USA). Data were compared between groups by Kruskall-Wallis $\mathrm{H}$ test and post-hoc Mann-Whitney $U$ test. Results represent the mean \pm standard deviation, and $P<0.05, P<0.01$ and $P<0.001$ were considered to indicate levels of statistically significant difference.

\section{Results}

\section{Hypertonicity influences proliferation and survival of chondrocytes}

We first determined the influence of tonicity on proliferation: OA HACs isolated at $580 \mathrm{mOsm}$ hardly attached or proliferated (Figure 1d), and 2 days after seeding no viable cells were recovered. At $280 \mathrm{mOsm}, 380 \mathrm{mOsm}$ and 480 mOsm, respectively, cells did adhere but increasing tonicity induced marked morphological changes: at 280 mOsm, cells appeared fibroblast-like, stretched out and flattened with long filopodia (Figure 1a); while at 380 mOsm, cells were more sphere-shaped and had shorter filopodia (Figure 1b). At $480 \mathrm{mOsm}$, cells showed few filopodia and appeared spherical (Figure 1c). The differences in appearance remained throughout the dedifferentiation period (P0 to P3), but were most apparent at earlier passages.

Using cell counts and DNA assays, doubling times were calculated from growth curves established from each passage at three different tonicities $(280 \mathrm{mOsm}, 380 \mathrm{mOsm}$ and $480 \mathrm{mOsm})$. Throughout dedifferentiation, OA HACs isolated at $480 \mathrm{mOsm}$ showed severely inhibited proliferation compared with cells at $280 \mathrm{mOsm}$ and 380 mOsm (Table 1). In contrast, doubling times of OA HACs at $280 \mathrm{mOsm}$ and $380 \mathrm{mOsm}$ never significantly differed (Table 1). All further experiments were therefore performed at $380 \mathrm{mOsm}$ (as high tonicity condition) and compared with 280 mOsm (control condition).

\section{Isolation and expansion of chondrocytes under hypertonic} conditions improves their phenotype

Next, we set out to determine whether expansion culture in physiological tonicity improves the chondrocytic phe- notype. Physiological tonicity (380 mOsm) during isolation and subsequent passaging of OA HACs significantly increased mRNA levels of both AGC1 (Figure 2a) and $S O X 9$ (Figure 2b) at all passages. In expanded P3 chondrocytes in physiological culture, $A G C 1$ levels were still higher than in unpassaged P0 chondrocytes cultured under the standard culture conditions (280 mOsm).

Physiological tonicity also significantly upregulated COL2 levels from 8.5-fold in P0 to 11.6-fold in expanded P3 chondrocytes (Figure 2c) compared with controls. In contrast, COL1 expression was significantly suppressed in physiological conditions throughout culture. Consequently, we found a significantly improved COL2/COL1 ratio during chondrocyte expansion (Figure 2d), from sevenfold in P0 cells to 100-fold in expanded P3 cells. Physiological tonicity also upregulated COL2 protein expression (Figure 2e): levels significantly increased (between 1.5-fold and 2.2-fold) in P0, P1 and P2 chondrocytes. In contrast, physiological tonicity significantly decreased COL1 protein expression (Figure 2f), from twofold in P0 cells to 13-fold in P1 cells.

Physiological tonicity also significantly increased $A G C 1$ (Figure 3a) and SOX9 (Figure 3b) mRNA levels in nonosteoarthritic human articular chondrocytes (NHACs). Furthermore, COL2 mRNA levels were significantly upregulated, from 5.8-fold in P0 cells to 270-fold in expanded P3 NHACs (Figure 3c). As in OA HACs, hypertonicity also downregulated COL1 expression with increasing passage number in NHACs: the COL2/COL1 ratios increased during expansion (Figure $3 \mathrm{~d}$ ), from 6.8fold in P0 cells to 355-fold in expanded P3 cells. Correspondingly, COL2 protein levels increased under these conditions (4.8-fold in P1 cells and 2.9-fold in P2 cells), while the amount of COL1 diminished (by 4.7-fold in P1 cells and fivefold in P2 cells) (Figure 3e, f).

\section{Hypertonicity activates NFAT5 in human articular chondrocytes}

Compared with 280 mOsm controls, NFAT5 mRNA levels were significantly increased in 380 mOsm OA HAC cultures (Figure 4a), as was the expression of established NFAT5 target genes $100 A 4$ (in all passages; Figure $4 \mathrm{~b}$ ) and SLC6A12 (until P2; Figure 4c). Similar effects were found in NHACs (data not shown).

\section{NFAT5 knockdown inhibits hypertonicity-induced chondrogenic marker expression}

Upon transduction, sorted eGFP-coexpressing OA HACs were switched to $380 \mathrm{mOsm}$ for 24 hours. In controls not expressing NFAT5-specific shRNAs, an approximately twofold increase in NFAT5 mRNA levels was observed upon hypertonic stimulation (Figure 4a, P1). In contrast, likewise challenged cells expressing anti-NFAT5 shRNAs showed an approximately $75 \%$ reduction in NFAT5 levels 


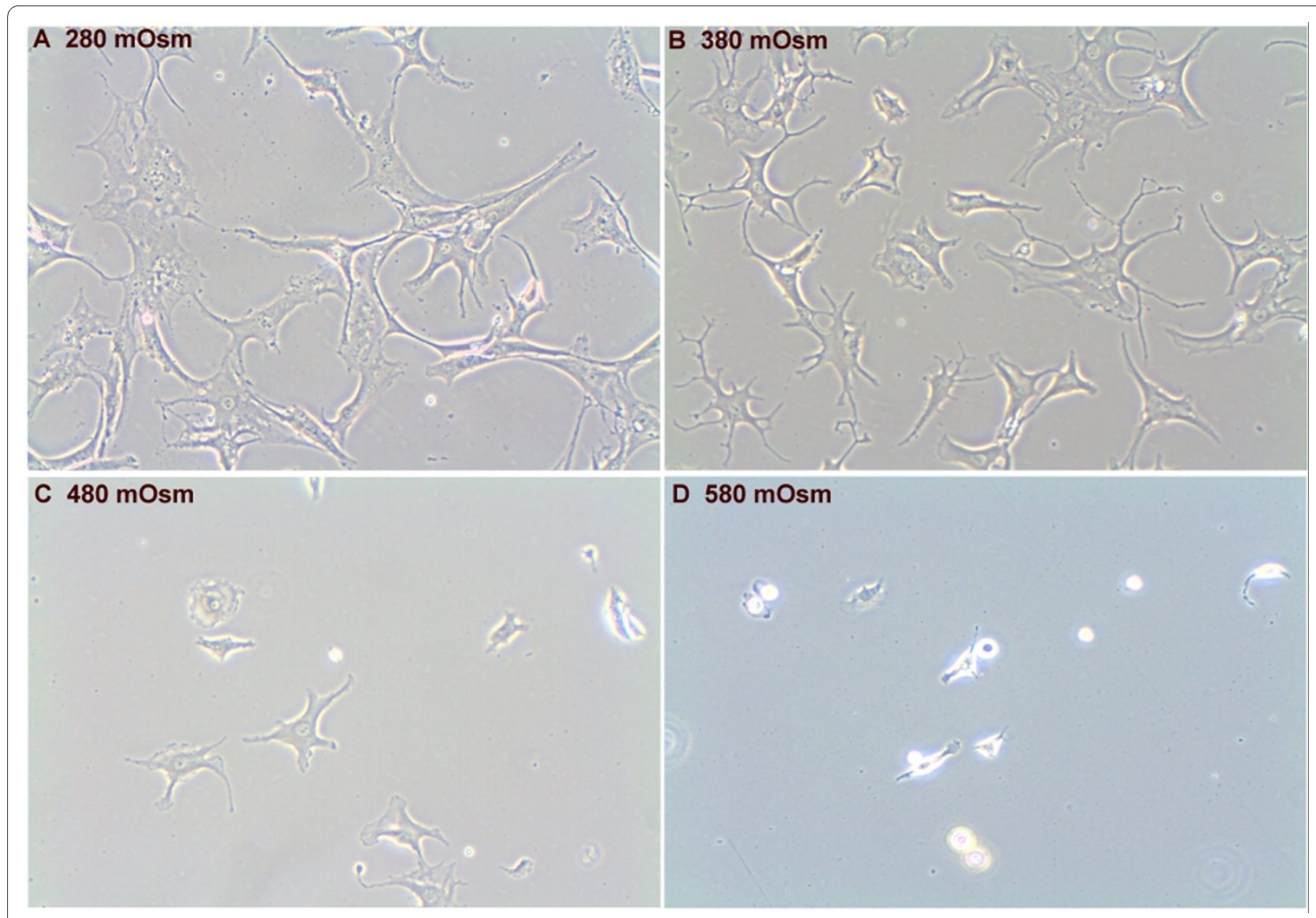

Figure 1 Hypertonic isolation and expansion of chondrocytes changes chondrocyte morphology. Representative images (200x) of chondrocytes cultured for 2 days at (a) 280 mOsm, (b) 380 mOsm, (c) 480 mOsm and (d) 580 mOsm.

(Figure 5a). Following NFAT5 knockdown, the NFAT5 targets $S 100 A 4$ and SLC6A12 were also no longer hypertonically inducible: $S 100 A 4$ expression decreased twofold and SLC6A12 was virtually undetectable upon NFAT5 RNAi (Figure 5a), confirming a functional NFAT5 knockdown. At 380 mOsm, NFAT5 RNAi also downregulated chondrogenic markers: $A G C 1$ by $80 \%$, SOX 9 by $32 \%$ and COL 2 by $84 \%$, as compared with non-RNAi controls (Figure 5b). Interestingly, expression of COL1 increased after
NFAT5 RNAi in OA HACs to $300 \%$ of control levels (Figure 5b).

\section{Discussion}

Isolation and expansion of adult HACs under physiological tonicity $(380 \mathrm{mOsm})$ improves expression of chondrogenic markers on mRNA and protein levels. While other studies partially confirm that nonhuman chondrocytes respond to tonicity with altered aggrecan and SOX9 expression $[4,8,10]$, we are reporting beneficial effects of

Table 1: Proliferation of chondrocytes isolated and cultured at $280 \mathrm{mOsm}, 380 \mathrm{mOsm}$ and $480 \mathrm{mOsm}$

\section{Chondrocyte proliferation (\%)}

\begin{tabular}{lllll}
\cline { 2 - 5 } Culture condition & Passage 0 & Passage 1 & Passage 2 & Passage 3 \\
\hline 280 mOsm & $100(68 \pm 28$ hours $)$ & $100(89 \pm 54$ hours $)$ & 100 (67 \pm 48 hours $)$ & 100 (57 \pm 11 hours $)$ \\
380 mOsm & $113 \pm 18$ & $89 \pm 25$ & $99 \pm 9$ & $154 \pm 41$ \\
480 mOsm & $675 \pm 405^{*}$ & $180 \pm 24^{*}$ & $168 \pm 28^{*}$ & $165 \pm 81^{*}$ \\
\hline
\end{tabular}

Data presented as relative doubling times in percentage of cells cultured at $280 \mathrm{mOsm}$, mean \pm standard deviation. The absolute doubling time \pm standard deviation in hours is displayed in brackets. $\mathrm{n}=6$. mOsm, milliosmoles per kilogram of water. ${ }^{*} P<0.05$. 
A

AGC1

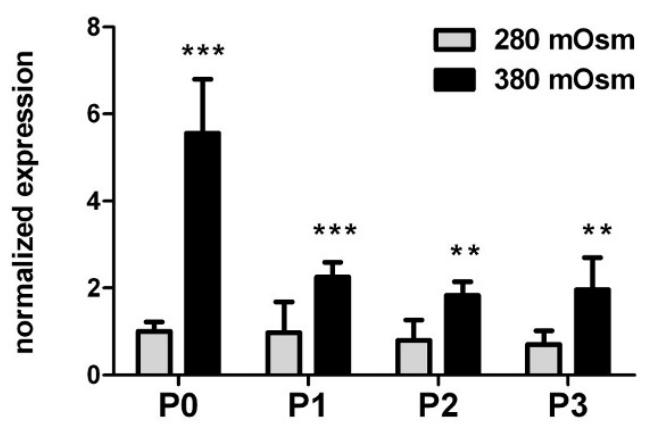

C

COL2

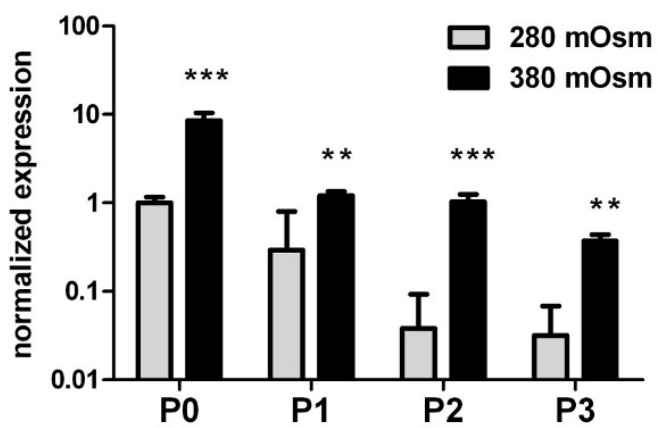

E

COL2 protein

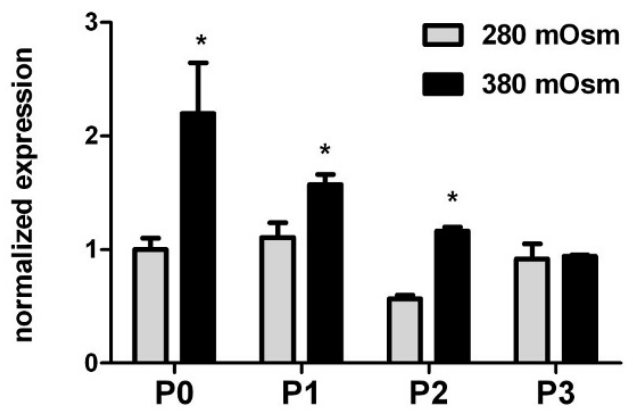

COL2

$\alpha-$ Tub
B

Sox9

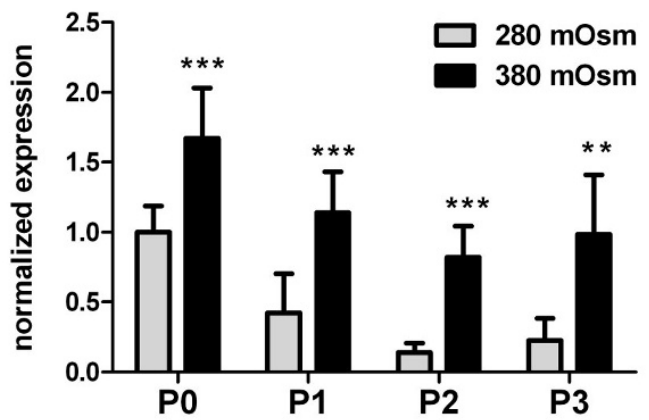

D

COL2:COL1

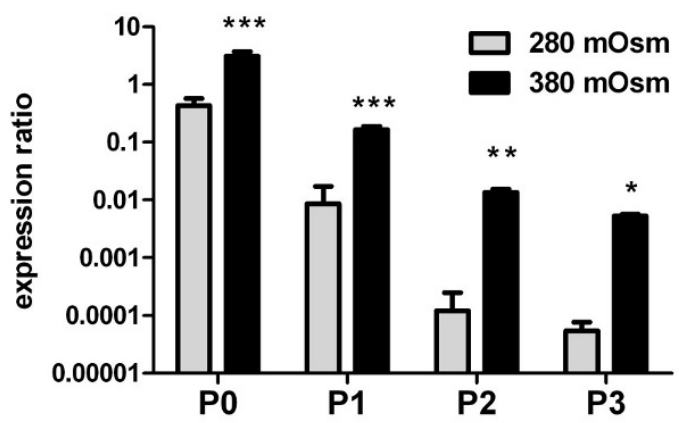

$\mathbf{F}$

COL1 protein

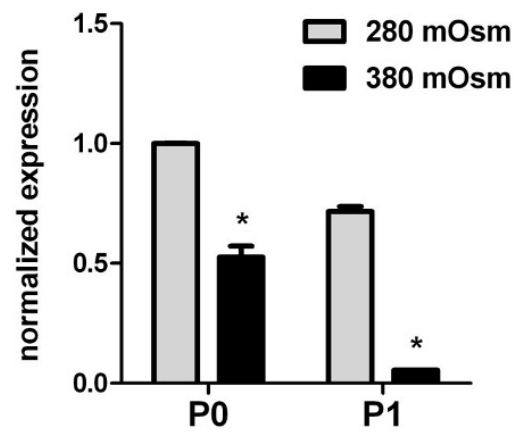

COL1

$\alpha$-Tub

Figure 2 Hypertonic isolation and expansion increased marker gene expression in osteoarthritis human articular chondrocytes. Relative expression of (a) AGC1, (b) SOX9, (c) COL2 and (d) COL2:COL1 ratio in primary (PO) and passaged (P1 to P3) chondrocytes cultured at 380 mOsm compared with $280 \mathrm{mOsm}$. (e) COL2 protein expression and (f) COL1 protein expression in P0 and P1 osteoarthritis human articular chondrocytes. Protein levels normalized to a-tubulin. Data are mean \pm standard deviation, $n=12$. Differences from cells cultured at 280 mOsm are indicated: ${ }^{*} P<0.05,{ }^{* *} P<0.01$ and ${ }^{* * *} P<0.001$. 


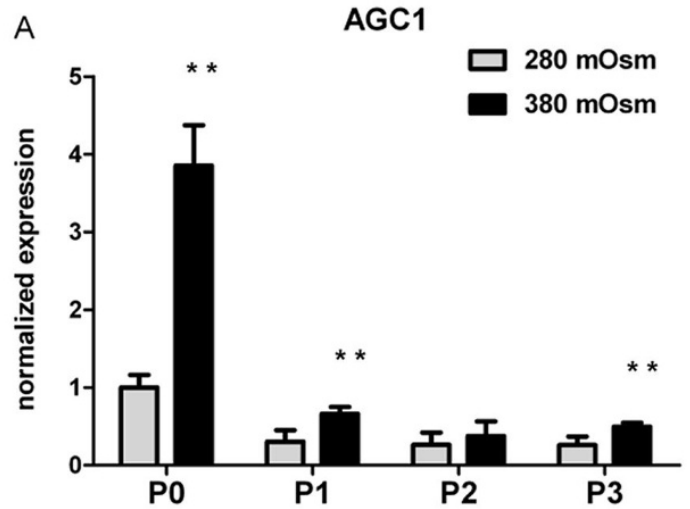

C

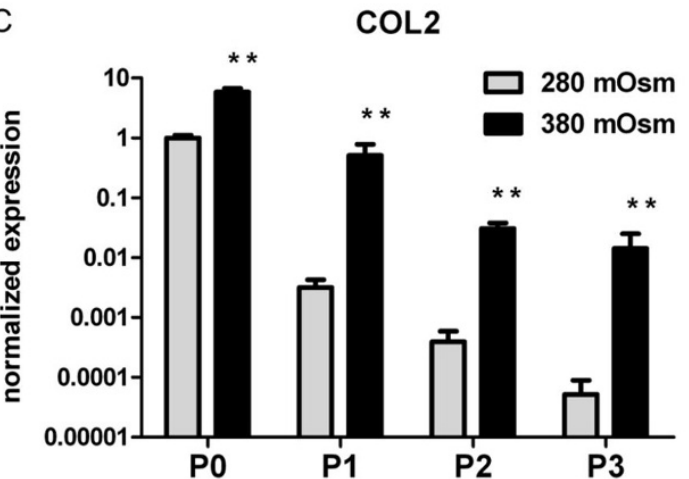

E

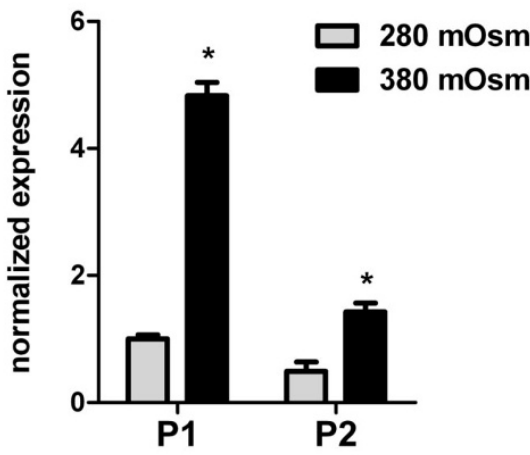

COL2

$\alpha-$ Tub
B $\quad$ sox 9

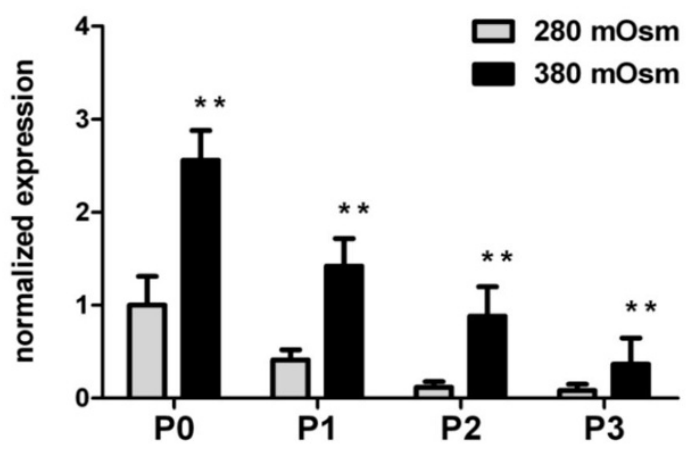

D

COL2:COL1

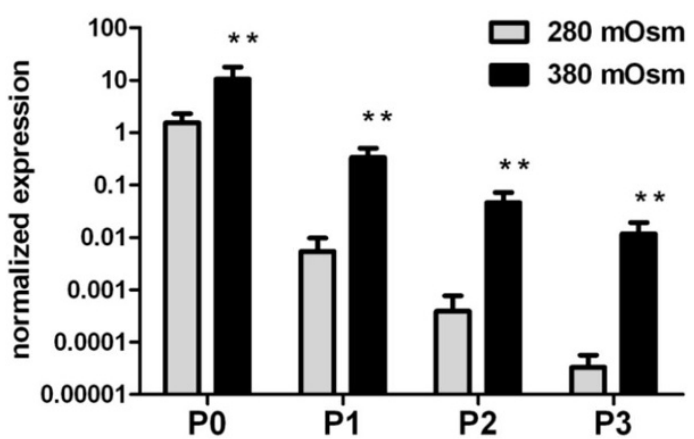

F $\quad$ COL1 protein

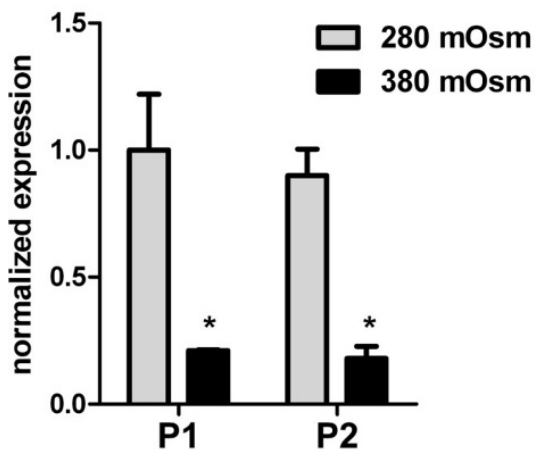

COL1

$\alpha-$ Tub

Figure 3 Hypertonic isolation and expansion increased chondrogenic marker expression in nonosteoarthritic human articular chondrocytes. Relative expression of (a) AGC1, (b) SOX9, (c) COL2 and (d) COL2:COL1 ratio in primary (P0) and passaged (P1 to P3) nonosteoarthritic human articular chondrocytes (NHACs) cultured at 380 mOsm compared with cells cultured at $280 \mathrm{mOsm}$. (e) COL2 protein expression and (f) COL1 protein expression in P1 and P2 NHACs, normalized to a-tubulin. Data are mean \pm standard deviation, $n=6$. Differences from 280 mOsm controls are indicated: ${ }^{*} P<0.05$ and ${ }^{*} P<0.01$. 

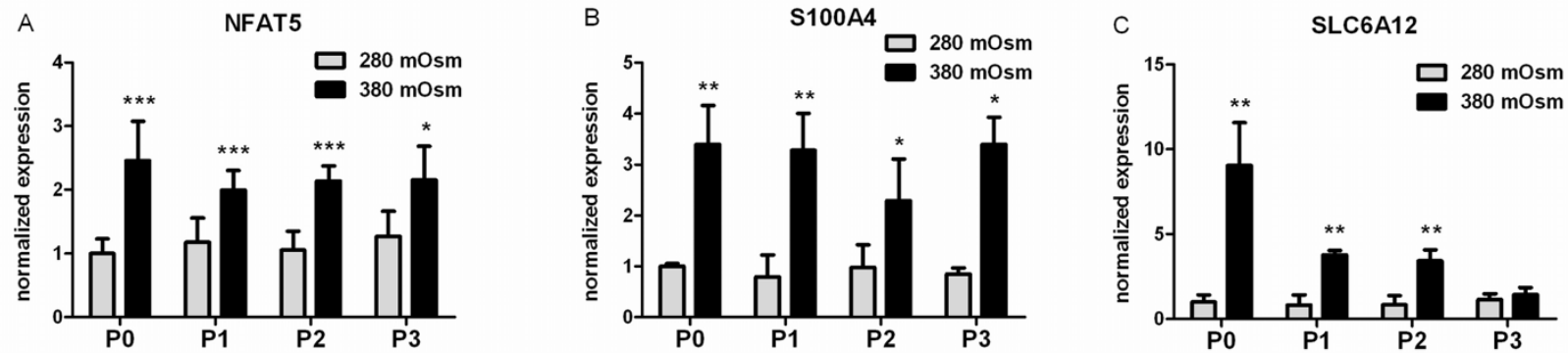

Figure 4 Hypertonic conditions activate nuclear factor of activated T-cells $\mathbf{5}$ in osteoarthritis human articular chondrocytes. Relative expression of (a) nuclear factor of activated T-cells 5 (NFAT5) and its target genes (b) S100A4 and (c) SLC6A12 in primary (P0) and passaged (P1 to P3) chondrocytes cultured at 380 mOsm compared with 280 mOsm. Data are mean \pm standard deviation, $n=12$. Differences are indicated: ${ }^{*} P<0.05$, ${ }^{* *} P<0.01$ and ${ }^{* *} P<0.001$.

isolating and expanding human normal and OA articular chondrocytes at physiological levels (380 mOsm). In addition, we also studied collagen type II expression, generally acknowledged to be the most important chondrogenic marker. As fibrocartilaginous collagen type I and hyaline collagen type II expression are differentially regulated in chondrocytes [34], analyzing the collagen type II/ type I expression ratios is informative of chondrogenic
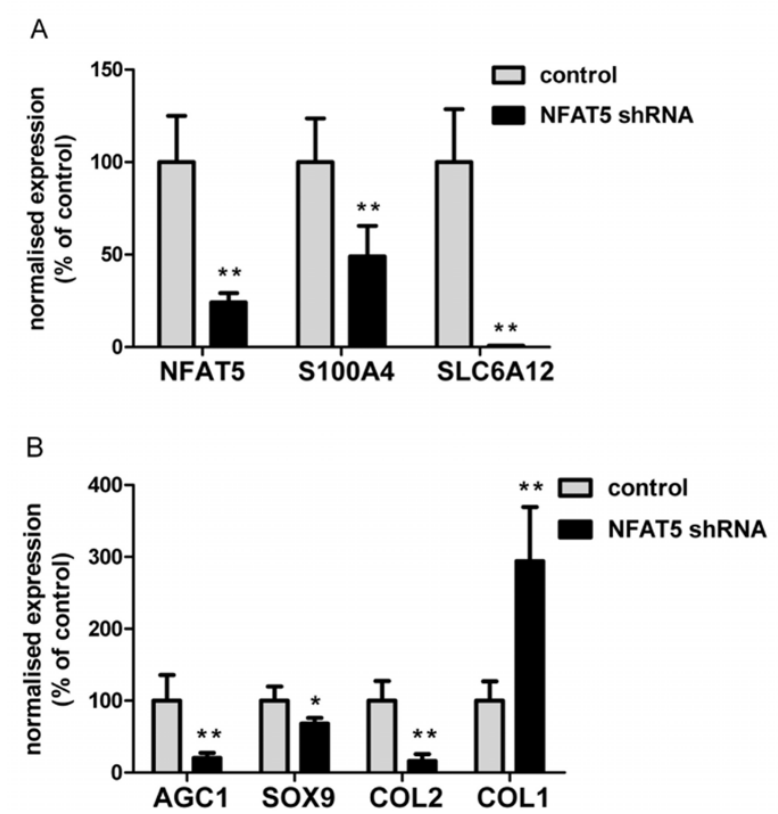

Figure $\mathbf{5}$ Nuclear factor of activated T-cells $\mathbf{5}$ knockdown inhibits hypertonicity-induced chondrogenic marker expression. (a) Relative expression of nuclear factor of activated T-cells 5 (NFAT5) and its target genes S100A4 and SLC6A12 in transduced chondrocytes either expressing (NFAT5 shRNA) or not expressing (control) NFAT5-specific shRNAs, 24 hours after increasing tonicity to $380 \mathrm{mOsm}$. (b) Effects of NFAT5 knockdown on chondrogenic markers AGC1, SOX9, COL2 and COL1. Data are mean \pm standard deviation, $n=6$. Differences from cells transduced with control virus are indicated: ${ }^{*} P<0.05$ and ${ }^{* *} P<0.01$. potential [51]. Interestingly, NFAT5 seems to be crucially involved in this differential regulation upon hypertonic challenge: it positively regulates collagen type II, while suppressing collagen type I (Figure 5b). Fibrocartilage, occurring in areas subject to frequent stress like intervertebral discs and tendon attachment sites, is more rich in collagen type I than is hyaline cartilage [55]. Tonicity may thus provide a simple means to manipulate expression of these two collagens for broader applications than regenerative chondrocyte implantations (autologous chondrocyte implantation or characterized chondrocyte implantation) alone [56].

Under our conditions, COL2 mRNA abundances measured by quantitative PCR correlated well with protein synthesis as determined by Western blots (Figures 2 and $3)$. The same observation holds for COL1 expression in the early passages, but not for COL1 expression in the later passages.

Hypertonicity induced an increase in NFAT5 abundance, and protein synthesis rates were found to be proportional to the increase in MRNA in MDCK cells [28] and mIMCD3 cells [27]. NFAT5 mRNA is expressed abundantly in chondrocytes throughout passages and is further induced by hypertonicity. However, we failed to show NFAT5 protein expression by Western blotting. Whether this failure is due to low protein abundance in our cells or technical issues such as poor extraction efficiency of this very large transcription factor remains to be elucidated in future experiments.

Hypertonicity induces cell shrinkage, which may activate $\mathrm{Na}^{+}, \mathrm{K}^{+}$, or $2 \mathrm{Cl}^{-}$co-transport, allowing cellular accumulation of $\mathrm{NaCl}$ and $\mathrm{KCl}$. The beneficial effects on chondrogenic marker gene expression therefore could have been caused by accumulation of specific inorganic ions or specific channel activity rather than primarily tonicity-mediated effects. We used NMDG-Cl, a bulky substitute for small cations that is impermeable to almost all known channels [57], and sucrose to exclude sodium- 
specific or chloride-specific effects. We were not able to detect any significant differences in gene expression patterns between the $\mathrm{NaCl}$, NMDG-Cl or sucrose methods of tonicity alteration (data not shown).

As our initial studies concerned adult HACs obtained from OA knee joints, we aimed at eliminating interpretation bias due to the pathological state of these cells. Using identically challenged NHACs, we showed that these chondrocytes react similarly to the same order of tonicity with respect to our marker genes: 380 mOsm significantly delayed the phenotypical deterioration of NHACs as observed in control medium. This may imply that physiological tonicity, postulated to be around 380 mOsm for chondrocytes, is sensed by OA cells and normal cells in a similar fashion. We observed a slightly faster decrease in $A G C 1$ and COL2 mRNA levels in P2 and P3 NHACs as compared with OA HACs. Late-stage OA chondrocytes from fibrillated areas are dedifferentiated, flattened cells. The loss of a proper spherical shape as an integral part of the chondrocytes phenotype $[58,59]$ involves cytoskeletal changes [60]. Exposing these cells to physiological tonicity as a redifferentiation stimulus probably induces a more enduring response as compared with spherical, normal chondrocytes. Cell-based therapies using the latter are usually restricted to younger individuals after traumatic insults. Autologous chondrocyte implantation employing OA cells may benefit relatively more from a hypertonic treatment protocol.

The precise molecular mechanism by which tonicity is sensed by cells is still poorly understood. Hypertonicityincreased NFAT5 mRNA abundances have been shown for other cell types [26-28]. NFAT5 is thus accepted as key transcription factor participating in the mammalian hypertonic stress response. Our study is the first showing the functional expression of NFAT5 in HACs. In both OA and normal chondrocytes, cellular NFAT5 mRNA levels are increased by $380 \mathrm{mOsm}$. In addition, mRNA levels of the generally accepted NFAT5 target genes, S100A4 and SLC6A12 [20,61], were induced accordingly after hypertonic challenge, underscoring an involvement of NFAT5. It has recently been suggested that guanine nucleotide exchange factors near the plasma membrane may be activated through cytoskeleton changes or by changes in interactions with putative osmosensors at the cell membrane in other cells [62]. The sensation of such basic responses might not be different in chondrocytes than in other cells. Rho-type small G proteins [63] and p38 kinases $[64,65]$ might also act upstream of NFAT5 in chondrocytes. In IMCD cells, p38 mitogen-activated protein kinase (MAPK) signaling was recently also shown to be involved in the NFAT5-mediated hypertonic induction of the osmosensitive $[66,67]$ serine-threonine protein kinase Sgk-1 [68,69]. As p38 MAPK plays important roles in chondrocytes and seems to be necessary for NFAT5 expression [20], further experiments employing pharmacological inhibition or knockdown experiments in HACs will hopefully shed more light into this signaling cascade in chondrocytes.

An increase in NFAT5 mRNA is usually transient with a cell type-dependent time course and a twofold to fourfold upregulation [26,28], which fits with our data. NFAT5 mRNA abundance might rapidly increase upon hypertonic stress by a transient increase in its mRNA stability, mediated by its 5 '-untranslated region [27]. Whether 380 mOsm is a sufficiently high tonicity to explain our increase in mRNA by this phenomenon, or whether active transcription is involved, has to be addressed in other studies. Interestingly, Tew and colleagues showed very recently that the mRNA of $S O X 9$, an important regulator of COL2 expression, is stabilized by supraphysiological tonicity [70]. Therefore, 380 mOsm might also directly contribute to SOX9 mRNA stability and abundance in our experiment, rather than elevating promoter activity. COL2 regulation could thus be an indirect effect of tonicity.

Interestingly, AGC1 seems to be more stably expressed in cultures maintained at 280 mOsm compared with 380 mOsm, with a lower overall expression in the former condition. Effects of tonicity on promoter activity and mRNA stability of $A G C 1$ are incompletely understood. Other groups have described the complexity of osmotic stress on gene expression [71,72]. It is tempting to speculate that gene expression may be influenced by morphological changes between our conditions: while cells cultured at 380 mOsm are rather round, cells cultured in monolayer at $280 \mathrm{mOsm}$ are rather flat and more fibroblast-like (see Figure 1). Although we did not investigate actin stress fiber formation in the present study, they are usually more pronounced in fibroblastic cells and have been shown to suppress SOX9 mRNA levels in chondrocytes [50].

Aggrecan expression, however, has been reported to be influenced by both hypertonicity and hypotonicity $[4,8]$. The promoter regions of both collagen type II and $A G C 1$ contain a plethora of potential other binding sites for transcriptional enhancers and suppressors, such as SOX5/6 [73,74], Barx2 [75], $\beta$-catenin [76], c-Maf [77], PIAS [78], TRAP230 [79], Bapx1 [80], and C/EBP and NF- $\mathrm{KB}$ [81]. Chondrogenic differentiation and the SOX9 dependency of aggrecan and collagen expression may also be differentially modulated by these transcriptional cofactors under different tonicities. Interestingly, while the SOX9 dependency of COL2A1 expression has been unequivocally shown, it may not actually be a key regulator of COL2A1 promoter activity in human adult articular chondrocytes [82]. Of note, the human aggrecan promoter sequence has been shown to contain a conserved NFAT5 binding site [83]. In nucleus pulposus cells, 
SOX9-mediated aggrecan expression has recently been shown to critically depend on PI3K/AKT signaling [84]. Moreover, while high $\mathrm{NaCl}$ rapidly activates p38 MAPK, its action can be isoform specific and may exert opposing effects on NFAT5 [85], which in turn may influence COL2A1 and AGC1 transcription differently in a tonicitydependent manner. We are therefore currently looking into the underlying molecular mechanisms regulating AGC1 and COL2 expression in both conditions.

With respect to regenerative medical applications, the high-end hypertonic conditions used by Tew and colleagues can be considered a limitation of that study. In our hands, these tonicity levels $(\geq 480 \mathrm{mOsm})$ induced chondrocyte death within 48 hours (Figure 1d) and are probably not applicable for chondrocyte expansion culture. To ensure sufficient cell numbers for cell-based repair techniques, the proliferation capacity of the isolated chondrocytes should not be compromised. Cell numbers generally need to be increased during two passages ( $>4$ to 10 times) for clinical application $[86,87]$. We found that supraphysiological conditions $(480 \mathrm{mOsm}$ and $580 \mathrm{mOsm}$ ) clearly compromised survival rates, which is in agreement with data by Racz and colleagues [17]. From our data, we conclude that about $380 \mathrm{mOsm}$ is optimal for both isolation and in vitro expansion culture of HACs.

NFAT5 knockdown downregulates its own transcription by $75 \%$ and compromises target gene induction (Figure 5), being in line with functionally active NFAT5 in chondrocytes. Constitutive homodimeric NFAT5 molecules encircle DNA rather independently of tonicity in solution [88], enabling NFAT5 to exert its biological activity over a wide tonicity range $[89,90]$. It is thus reasonable to assume that NFAT5 activity is not generally compromised at $380 \mathrm{mOsm}$. However, other aspects are involved in the regulation of NFAT5 as well as its target genes. Like other proteins larger than $50 \mathrm{kDa}$ [91], NFAT5 depends on nuclear localization and export sequences for its nuclear translocation $[26,88,91]$. In most cells, NFAT5 is equally distributed between the cytoplasm and the nucleus at physiological tonicity $( \pm 300$ mOsm), whereas at $500 \mathrm{mOsm}$ most of it localizes to the nucleus $[19,26,89]$.

To demonstrate that the hypertonicity-induced chondrogenic marker expression was indeed mediated by NFAT5, we used RNAi to confirm that knockdown of NFAT5 significantly inhibited hypertonic induction of its own transcription as discussed before, significantly suppressed the tonicity-mediated induction of known NFAT5 targets, and, most importantly, significantly eliminated the hypertonicity-mediated mRNA expression of chondrogenic marker genes (COL2, AGC1, SOX9 and COL1).

\section{Conclusions}

We have shown that isolation and expansion of adult HACs in culture medium of physiological tonicity ( 380 mOsm) improves chondrogenic marker expression and extracellular matrix production through NFAT5. We identified NFAT5 as a novel molecular target preserving chondrocytic marker expression. Our data provide valuable insights for the development of strategies for cellbased repair of chondral lesions, and contribute to the understanding of mechanisms involving OA.

\section{Abbreviations}

DMEM: Dulbecco's modified Eagle's medium; eGFP: enhanced green fluorescent protein; FACS: fluorescence-activated cell sorting; FCS: fetal calf serum; HAC: human articular chondrocyte; MAPK: mitogen-activated protein kinase; mOsm: milliosmoles per kilogram of water; NF: nuclear factor; NFAT: nuclear factor of activated T cells; NHAC: nonosteoarthritic human articular chondrocyte; NMDG-Cl: N-methyl-d-glucamine chloride; OA: osteoarthritis; PBS: phosphate-buffered saline; PCR: polymerase chain reaction; P: passage; RNAi: RNA interference; RT: reverse transcriptase; TonEBP: Tonicity-responsive Enhancer Binding Protein.

\section{Competing interests}

The authors declare that they have no competing interests.

\section{Authors' contributions}

$\mathrm{HJ}$ conceived the study. AEvdW, HW, JANV and HJ designed the study. AEvdW, $\mathrm{EH}$ and RHJD analyzed the data. AEvdW, EH, NK, TJMW and MMJC performed the experiments. NPVT, TJMW and MMJC contributed the reagents/materials/ analysis tools. AEvdW and HJ wrote the paper. All authors read and approved the final manuscript.

\section{Acknowledgements}

The authors thank A Prins (Erasmus Medical Center Rotterdam, Department of Hematology, The Netherlands) for his expert FACS sorting and analysis, and Dr Peter de Boer (UMC St Radboud, Department of Obstetrics and Gynaecology, The Netherlands) for critical reading of the manuscript. The present work was supported by the Dutch Program for Tissue Engineering (project RGT6738) and the Dutch Arthritis Association (project LLP11).

\section{Author Details}

1Department of Orthopaedics, Erasmus MC, University Medical Center Rotterdam, Dr. Molewaterplein 50, 3015 GE Rotterdam, The Netherlands, 2Department of Orthopaedic Surgery, GROW school for Oncology and Developmental Biology, Maastricht University Medical Center,

Universiteitssingel 40, 6202 AZ Maastricht, The Netherlands and ${ }^{3}$ Department of Hematology, Erasmus MC, University Medical Center Rotterdam, Dr. Molewaterplein 50, 3015 GE Rotterdam, The Netherlands

Received: 9 February 2010 Revised: 28 April 2010

Accepted: 21 May 2010 Published: 21 May 2010

\section{References}

1. Mow VC, Hayes WC, editors: Basic Orthopaedic Biomechanics LippincottRaven, Philadelphia, PA; 1997.

2. Lesperance LM, Gray ML, Burstein D: Determination of fixed charge density in cartilage using nuclear magnetic resonance. J Orthop Res 1992, 10:1-13.

3. Maroudas Al: Balance between swelling pressure and collagen tension in normal and degenerate cartilage. Nature 1976, 260:808-809.

4. Urban JP, Hall AC, Gehl KA: Regulation of matrix synthesis rates by the ionic and osmotic environment of articular chondrocytes. J Cell Physiol 1993, 154:262-270.

5. Urban JP: The chondrocyte: a cell under pressure. Br J Rheumatol 1994, 33:901-908.

6. Bank RA, Soudry M, Maroudas A, Mizrahi J, TeKoppele JM: The increased swelling and instantaneous deformation of osteoarthritic cartilage is 
highly correlated with collagen degradation. Arthritis Rheum 2000, 43:2202-2210.

7. Bush PG, Hall AC: Passive osmotic properties of in situ human articular chondrocytes within non-degenerate and degenerate cartilage. J Cell Physiol 2005, 204:309-319.

8. Palmer GD, Chao Ph PH, Raia F, Mauck RL, Valhmu WB, Hung CT: Timedependent aggrecan gene expression of articular chondrocytes in response to hyperosmotic loading. Osteoarthritis Cartilage 2001, 9:761-770.

9. Bush PG, Hall AC: Regulatory volume decrease (RVD) by isolated and in situ bovine articular chondrocytes. J Cell Physiol 2001, 187:304-314.

10. Hung CT, LeRoux MA, Palmer GD, Chao PH, Lo S, Valhmu WB: Disparate aggrecan gene expression in chondrocytes subjected to hypotonic and hypertonic loading in 2D and 3D culture. Biorheology 2003, 40:61-72.

11. Negoro K, Kobayashi S, Takeno K, Uchida K, Baba H: Effect of osmolarity on glycosaminoglycan production and cell metabolism of articular chondrocyte under three-dimensional culture system. Clin Exp Rheumatol 2008, 26:534-541.

12. Burg MB: Macromolecular crowding as a cell volume sensor. Cell Physiol Biochem 2000, 10:251-256.

13. Neuhofer W, Woo SK, Na KY, Grunbein R, Park WK, Nahm O, Beck FX, Kwon HM: Regulation of TonEBP transcriptional activator in MDCK cells following changes in ambient tonicity. Am J Physio/ Cell Physiol 2002, 283:C1604-C1611.

14. Yancey PH, Clark ME, Hand SC, Bowlus RD, Somero GN: Living with water stress: evolution of osmolyte systems. Science 1982, 217:1214-1222.

15. Kultz D, Chakravarty D: Hyperosmolality in the form of elevated $\mathrm{NaCl}$ but not urea causes DNA damage in murine kidney cells. Proc Natl Acad Sci USA 2001, 98:1999-2004.

16. Woo SK, Lee SD, Kwon HM: TonEBP transcriptional activator in the cellular response to increased osmolality. Pflugers Arch 2002, 444:579-585.

17. Racz B, Reglodi D, Fodor B, Gasz B, Lubics A, Gallyas F Jr, Roth E, Borsiczky $B$ : Hyperosmotic stress-induced apoptotic signaling pathways in chondrocytes. Bone 2007, 40:1536-1543.

18. Burg MB, Kwon ED, Kultz D: Regulation of gene expression by hypertonicity. Annu Rev Physiol 1997, 59:437-455.

19. Miyakawa H, Woo SK, Dahl SC, Handler JS, Kwon HM: Tonicity-responsive enhancer binding protein, a rel-like protein that stimulates transcription in response to hypertonicity. Proc Natl Acad Sci USA 1999, 96:2538-2542

20. Lopez-Rodriguez C, Antos CL, Shelton JM, Richardson JA, Lin F, Novobrantseva TI, Bronson RT, Igarashi P, Rao A, Olson EN: Loss of NFAT5 results in renal atrophy and lack of tonicity-responsive gene expression. Proc Natl Acad Sci USA 2004, 101:2392-2397.

21. Na KY, Woo SK, Lee SD, Kwon HM: Silencing of TonEBP/NFAT5 transcriptional activator by RNA interference. J Am Soc Nephrol 2003, 14:283-288

22. Kasono K, Saito T, Tamemoto H, Yanagidate C, Uchida S, Kawakami M, Sasaki S, Ishikawa SE: Hypertonicity regulates the aquaporin-2 promoter independently of arginine vasopressin. Nephrol Dial Transplant 2005, 20:509-515.

23. Chen $M$, Sinha M, Luxon BA, Bresnick AR, O'Connor KL: Integrin $a_{6} \beta_{4}$ controls the expression of genes associated with cell motility, invasion, and metastasis, including S100A4/metastasin. J Biol Chem 2009, 284:1484-1494

24. Ito T, Kimura Y, Uozumi Y, Takai M, Muraoka S, Matsuda T, Ueki K, Yoshiyama M, Ikawa M, Okabe M, Schaffer SW, Fujio Y, Azuma J: Taurine depletion caused by knocking out the taurine transporter gene leads to cardiomyopathy with cardiac atrophy. J Mol Cell Cardiol 2008, 44:927-937.

25. Nakamura N, Takenaga K: Hypomethylation of the metastasisassociated S100A4 gene correlates with gene activation in human colon adenocarcinoma cell lines. Clin Exp Metastasis 1998, 16:471-479.

26. Ko BC, Turck CW, Lee KW, Yang Y, Chung SS: Purification, identification, and characterization of an osmotic response element binding protein. Biochem Biophys Res Commun 2000, 270:52-61.

27. Cai Q, Ferraris JD, Burg MB: High NaCl increases TonEBP/OREBP mRNA and protein by stabilizing its mRNA. Am J Physiol Renal Physiol 2005, 289:F803-F807.
28. Woo SK, Dahl SC, Handler JS, Kwon HM: Bidirectional regulation of tonicity-responsive enhancer binding protein in response to changes in tonicity. Am J Physiol Renal Physiol 2000, 278:F1006-F1012.

29. Morancho B, Minguillon J, Molkentin JD, Lopez-Rodriguez C, Aramburu J: Analysis of the transcriptional activity of endogenous NFAT5 in primary cells using transgenic NFAT-luciferase reporter mice. BMCMol Bio/ 2008, 9:13.

30. Widuchowski W, Widuchowski J, Trzaska T: Articular cartilage defects: study of 25,124 knee arthroscopies. Knee 2007, 14:177-182.

31. Brittberg M, Lindahl A, Nilsson A, Ohlsson C, Isaksson O, Peterson L: Treatment of deep cartilage defects in the knee with autologous chondrocyte transplantation. N Eng/ J Med 1994, 331:889-895.

32. Saris DB, Vanlauwe J, Victor J, Haspl M, Bohnsack M, Fortems Y Vandekerckhove B, Almqvist KF, Claes T, Handelberg F, Lagae K, van der Bauwhede J, Vandenneucker $H$, Yang KG, Jelic M, Verdonk R, Veulemans $N$, Bellemans J, Luyten FP: Characterized chondrocyte implantation results in better structural repair when treating symptomatic cartilage defects of the knee in a randomized controlled trial versus microfracture. Am J Sports Med 2008, 36:235-246

33. von der Mark K, Gauss V, von der Mark H, Muller P: Relationship between cell shape and type of collagen synthesised as chondrocytes lose their cartilage phenotype in culture. Nature 1977, 267:531-532

34. Schnabel M, Marlovits S, Eckhoff G, Fichtel I, Gotzen L, Vecsei V, Schlegel J: Dedifferentiation-associated changes in morphology and gene expression in primary human articular chondrocytes in cell culture. Osteoarthritis Cartilage 2002, 10:62-70.

35. Benya PD, Padilla SR, Nimni ME: Independent regulation of collagen types by chondrocytes during the loss of differentiated function in culture. Cell 1978, 15:1313-1321.

36. Setton LA, Mow VC, Muller FJ, Pita JC, Howell DS: Altered structurefunction relationships for articular cartilage in human osteoarthritis and an experimental canine model. Agents Actions Suppl 1993, 39:27-48.

37. Loeser RF: Aging and osteoarthritis: the role of chondrocyte senescence and aging changes in the cartilage matrix. Osteoarthritis Cartilage 2009, 17:971-979.

38. Gouttenoire J, Valcourt U, Ronziere MC, Aubert-Foucher E, Mallein-Gerin F, Herbage D: Modulation of collagen synthesis in normal and osteoarthritic cartilage. Biorheology 2004, 41:535-542.

39. Das RH, van Osch GJ, Kreukniet M, Oostra J, Weinans H, Jahr H: Effects of individual control of $\mathrm{pH}$ and hypoxia in chondrocyte culture. J Orthop Res 2010, 28:537-45.

40. Karsten U, Wollenberger A: Improvements in the ethidium bromide method for direct fluorometric estimation of DNA and RNA in cell and tissue homogenates. Anal Biochem 1977, 77:464-470.

41. de Mos M, van der Windt AE, Jahr H, van Schie HT, Weinans H, Verhaar JA, van Osch GJ: Can platelet-rich plasma enhance tendon repair? A cell culture study. Am J Sports Med 2008, 36:1171-1178.

42. Stewart SA, Dykxhoorn DM, Palliser D, Mizuno H, Yu EY, An DS, Sabatin DM, Chen IS, Hahn WC, Sharp PA, Weinberg RA, Novina CD: Lentivirusdelivered stable gene silencing by RNAi in primary cells. RNA 2003, 9:493-501

43. Sigma-Aldrich [http://www.sigmaaldrich.com]

44. Dull T, Zufferey R, Kelly M, Mandel RJ, Nguyen M, Trono D, Naldini L: A third-generation lentivirus vector with a conditional packaging system. J Virol 1998, 72:8463-8471.

45. Zufferey R, Dull T, Mandel RJ, Bukovsky A, Quiroz D, Naldini L, Trono D: Self-inactivating lentivirus vector for safe and efficient in vivo gene delivery. J Virol 1998, 72:9873-9880.

46. Schambach A, Bohne J, Baum C, Hermann FG, Egerer L, von Laer D, Giroglou T: Woodchuck hepatitis virus post-transcriptional regulatory element deleted from $X$ protein and promoter sequences enhances retroviral vector titer and expression. Gene Ther 2006, 13:641-645.

47. Follenzi A, Naldini L: HIV-based vectors. Preparation and use. Methods Mol Med 2002, 69:259-274

48. Uitterlinden EJ, Jahr H, Koevoet JL, Jenniskens YM, Bierma-Zeinstra SM, Degroot J, Verhaar JA, Weinans H, van Osch GJ: Glucosamine decreases expression of anabolic and catabolic genes in human osteoarthritic cartilage explants. Osteoarthritis Cartilage 2006, 14:250-257.

49. van der Windt $A E$, Jahr $H$, Farrell $E$, Verhaar JA, Weinans $H$, van Osch GJ: Calcineurin inhibitors promote chondrogenic marker expression of dedifferentiated human adult chondrocytes via stimulation of endogenous TGF $\beta 1$ production. Tissue Eng Part A 16:1-10. 
50. Tew SR, Hardingham TE: Regulation of SOX9 mRNA in human articular chondrocytes involving p38 MAPK activation and mRNA stabilization. J Biol Chem 2006, 281:39471-39479.

51. Mandl EW, Jahr H, Koevoet JL, van Leeuwen JP, Weinans H, Verhaar JA, van Osch GJ: Fibroblast growth factor- 2 in serum-free medium is a potent mitogen and reduces dedifferentiation of human ear chondrocytes in monolayer culture. Matrix Biol 2004, 23:231-241.

52. Livak KJ, Schmittgen TD: Analysis of relative gene expression data using real-time quantitative PCR and the 2(- C(T)) method. Methods 2001, 25:402-408

53. Kraveka JM, Schady D, Obeid LM, Ogretmen B: Immunoprecipitation of human telomerase reverse transcriptase with telomerase activity. Anal Biochem 2001, 291:166-169.

54. ImageJ 1.42 software [http://rsb.info.nih.gov/ij/download.html]

55. Benjamin M, Ralphs JR: Biology of fibrocartilage cells. Int Rev Cytol 2004, 233:1-45.

56. Wuertz K, Urban JP, Klasen J, Ignatius A, Wilke HJ, Claes L, Neidlinger-Wilke C: Influence of extracellular osmolarity and mechanical stimulation on gene expression of intervertebral disc cells. J Orthop Res 2007 , 25:1513-1522.

57. Duranton C, Huber SM, Tanneur V, Brand VB, Akkaya C, Shumilina EV, Sandu CD, Lang F: Organic osmolyte permeabilities of the malariainduced anion conductances in human erythrocytes. J Gen Physiol 2004, 123:417-426.

58. Darling EM, Athanasiou KA: Retaining zonal chondrocyte phenotype by means of novel growth environments. Tissue Eng 2005, 11:395-403.

59. Murphy CL, Sambanis A: Effect of oxygen tension and alginate encapsulation on restoration of the differentiated phenotype of passaged chondrocytes. Tissue Eng 2001, 7:791-803.

60. Darling EM, Pritchett PE, Evans BA, Superfine R, Zauscher S, Guilak F: Mechanical properties and gene expression of chondrocytes on micropatterned substrates following dedifferentiation in monolayer. Cell Mol Bioeng 2009, 2:395-404.

61. Jeon US, Kim JA, Sheen MR, Kwon HM: How tonicity regulates genes: story of TonEBP transcriptional activator. Acta Physiol (Oxf) 2006, 187:241-247.

62. Kino T, Takatori H, Manoli I, Wang Y, Tiulpakov A, Blackman MR, Su YA, Chrousos GP, DeCherney AH, Segars JH: Brx mediates the response of lymphocytes to osmotic stress through the activation of NFAT5. SCi Signal 2009, 2:ra5.

63. Kelkar N, Standen CL, Davis RJ: Role of the JIP4 scaffold protein in the regulation of mitogen-activated protein kinase signaling pathways. Mol Cell Biol 2005, 25:2733-2743.

64. Lopez-Rodriguez C, Aramburu J, Rakeman AS, Rao A: NFAT5, a constitutively nuclear NFAT protein that does not cooperate with Fos and Jun. Proc Natl Acad Sci USA 1999, 96:7214-7219.

65. Ho SN: Intracellular water homeostasis and the mammalian cellular osmotic stress response. J Cell Physiol 2006, 206:9-15.

66. Nishida Y, Nagata T, Takahashi Y, Sugahara-Kobayashi M, Murata A, Asai S: Alteration of serum/glucocorticoid regulated kinase-1 (sgk-1) gene expression in rat hippocampus after transient global ischemia. Brain Res Mol Brain Res 2004, 123:121-125.

67. Rozansky DJ, Wang J, Doan N, Purdy T, Faulk T, Bhargava A, Dawson K, Pearce D: Hypotonic induction of SGK1 and $\mathrm{Na}^{+}$transport in $\mathrm{A} 6$ cells. Am J Physiol Renal Physiol 2002, 283:F105-F113.

68. Chen S, Grigsby CL, Law CS, Ni X, Nekrep N, Olsen K, Humphreys MH Gardner DG: Tonicity-dependent induction of Sgk1 expression has a potential role in dehydration-induced natriuresis in rodents. $J$ Clin Invest 2009, 119:1647-1658.

69. Webster MK, Goya L, Ge Y, Maiyar AC, Firestone GL: Characterization of sgk, a novel member of the serine/threonine protein kinase gene family which is transcriptionally induced by glucocorticoids and serum. Mol Cell Biol 1993, 13:2031-2040.

70. Tew S, Peffers M, McKay T, Lowe E, Khan W, Hardingham T, Clegg P: Hyperosmolarity regulates SOX 9 mRNA post transcriptionally in human articular chondrocytes. Am J Physiol Cell Physiol 2009, 297:C898-C906

71. Chao PH, West AC, Hung CT: Chondrocyte intracellular calcium, cytoskeletal organization, and gene expression responses to dynamic osmotic loading. Am J Physiol Cell Physiol 2006, 291:C718-C725.

72. Finan JD, Guilak F: The effects of osmotic stress on the structure and function of the cell nucleus. J Cell Biochem 109:460-467.
73. Ikeda T, Kamekura S, Mabuchi A, Kou I, Seki S, Takato T, Nakamura K, Kawaguchi H, Ikegawa S, Chung UI: The combination of SOX5, SOX6, and SOX9 (the SOX trio) provides signals sufficient for induction of permanent cartilage. Arthritis Rheum 2004, 50:3561-3573.

74. Lefebvre V, Behringer RR, de Crombrugghe B: L-Sox5, Sox6 and Sox9 control essential steps of the chondrocyte differentiation pathway. Osteoarthritis Cartilage 2001, 9(Suppl A):S69-S75.

75. Meech R, Edelman DB, Jones FS, Makarenkova HP: The homeobox transcription factor Barx2 regulates chondrogenesis during limb development. Development 2005, 132:2135-2146.

76. Akiyama H, Lyons JP, Mori-Akiyama Y, Yang X, Zhang R, Zhang Z, Deng JM, Taketo MM, Nakamura T, Behringer RR, McCrea PD, de Crombrugghe B: Interactions between Sox 9 and beta-catenin control chondrocyte differentiation. Genes Dev 2004, 18:1072-1087.

77. Huang W, Lu N, Eberspaecher H, De Crombrugghe B: A new long form of c-Maf cooperates with Sox9 to activate the type II collagen gene. J Biol Chem 2002, 277:50668-50675.

78. Hattori T, Eberspaecher H, Lu J, Zhang R, Nishida T, Kahyo T, Yasuda H, de Crombrugghe B: Interactions between PIAS proteins and SOX9 result in an increase in the cellular concentrations of SOX9. J Biol Chem 2006, 281:14417-14428

79. Zhou R, Bonneaud N, Yuan CX, de Santa Barbara P, Boizet B, Schomber T, Scherer G, Roeder RG, Poulat F, Berta P: SOX9 interacts with a component of the human thyroid hormone receptor-associated protein complex. Nucleic Acids Res 2002, 30:3245-3252.

80. Yamashita S, Andoh M, Ueno-Kudoh H, Sato T, Miyaki S, Asahara H: Sox 9 directly promotes Bapx 1 gene expression to repress Runx 2 in chondrocytes. Exp Cell Res 2009, 315:2231-2240.

81. Ushita M, Saito T, Ikeda T, Yano F, Higashikawa A, Ogata N, Chung U, Nakamura K, Kawaguchi H: Transcriptional induction of SOX9 by NF-kB family member RelA in chondrogenic cells. Osteoarthritis Cartilage 2009, 17:1065-1075

82. Aigner T, Gebhard PM, Schmid E, Bau B, Harley V, Poschl E: SOX9 expression does not correlate with type II collagen expression in adult articular chondrocytes. Matrix Biol 2003, 22:363-372.

83. Tsai TT, Danielson KG, Guttapalli A, Oguz E, Albert TJ, Shapiro IM, Risbud $\mathrm{MV}$ : TonEBP/OREBP is a regulator of nucleus pulposus cell function and survival in the intervertebral disc. J Biol Chem 2006, 281:25416-25424.

84. Cheng CC, Uchiyama Y, Hiyama A, Gajghate S, Shapiro IM, Risbud MV: $\mathrm{PI3K} / \mathrm{AKT}$ regulates aggrecan gene expression by modulating Sox 9 expression and activity in nucleus pulposus cells of the intervertebral disc. J Cell Physiol 2009, 221:668-676.

85. Zhou X, Ferraris JD, Dmitrieva NI, Liu Y, Burg MB: MKP-1 inhibits high $\mathrm{NaCl}$-induced activation of $\mathrm{p} 38$ but does not inhibit the activation of TOnEBP/OREBP: opposite roles of p38alpha and p38delta. Proc Natl Acad Sci USA 2008, 105:5620-5625.

86. Brittberg M: Autologous chondrocyte implantation - technique and long-term follow-up. Injury 2008, 39(Suppl 1):S40-S49.

87. Brittberg M, Peterson L, Sjogren-Jansson E, Tallheden T, Lindahl A: Articular cartilage engineering with autologous chondrocyte transplantation. A review of recent developments. J Bone Joint Surg Am 2003, 85-A(Suppl 3):109-115.

88. Lopez-Rodriguez C, Aramburu J, Rakeman AS, Copeland NG, Gilbert DJ, Thomas S, Disteche C, Jenkins NA, Rao A: NF-AT5: the NF-AT family of transcription factors expands in a new direction. Cold Spring Harb Symp Quant Biol 1999, 64:517-526.

89. Lopez-Rodriguez C, Aramburu J, Jin L, Rakeman AS, Michino M, Rao A: Bridging the NFAT and NF-KB families: NFAT5 dimerization regulates cytokine gene transcription in response to osmotic stress. Immunity 2001, 15:47-58

90. Lee SD, Woo SK, Kwon HM: Dimerization is required for phosphorylation and DNA binding of TonEBP/NFAT5. Biochem Biophys Res Commun 2002, 294:968-975.

91. Cyert MS: Regulation of nuclear localization during signaling. J Biol Chem 2001, 276:20805-20808.

doi: $10.1186 /$ ar3031

Cite this article as: van der Windt et al., Physiological tonicity improves human chondrogenic marker expression through nuclear factor of activated T-cells 5 in vitro Arthritis Research \& Therapy 2010, 12:R100 